\title{
Andy Warhol. El arte mecánico
}

Museo Picasso Málaga

Del 31 de mayo al 16 de septiembre de 2018

Quizás sea Andy Warhol (1928-1987) uno de los pocos artistas a los que le interesaba poco o nada lo que estaba representado en su obra. Como si el resultado final no tuviese ningún valor, y todo el proceso creativo sólo le incumbiese a él. Una actitud que recuerda a la idiosincrasia del mundo publicitario, cuyas ingeniosas campañas y sesudos estudios quedan reducidos a casi nada al ser trasladados a los mass-media. Siempre hay más de lo que somos capaces de percibir. Así pasa con la producción artística de Warhol, por mucho que se empeñe en que nos quedemos en la superficie de sus cuadros, a veces ni eso; a veces hay que salirse literalmente de estos para empezar a ver su contenido. Desde sus sopas Campbells, a sus sillas eléctricas y pinturas piss: lo importante no pasa en la imagen que tenemos delante, sino en lo que nos evoca de soslayo. Como si en vez de estar delante de un billete de dólar estuviésemos contemplando un gran paisaje abstracto, altamente emotivo, esos que a priori él mismo denostó y consiguió relegar a un segundo plano. Si hay algo que nos resulta novedoso de esta exposición, es la muestra de sus comienzos como ilustrador de moda, que nos recuerda el fuerte vínculo que estableció con los mecanismos intrínsecos de la publicidad, no solo en su modo de ejecución, tal como indica el título de la exposición, Andy Warhol. El arte mecánico, sino también en la forma de comunicarnos su contenido. Como se puede leer en el catálogo de la exposición: «Warhol como antiguo "manipulador" publicitario era plenamente consciente de las implicaciones del sentido superficial en la cultura de masas: él también había "vendido el ruido y no las nueces"”.

José Lebrero Stals comisaría esta retrospectiva que recoge una buena muestra de los diferentes campos artísticos por los que Warhol transitó: desde el diseño de tarjetas postales para Tiffany, o la grabación de videos experimentales y programas de televisión para la MTV, hasta su documentada vinculación con la escena musical underground de Nueva York. Todo ello da a conocer al visitante el perfil polifacético del artista, además de presentarlo como un verdadero hombre de negocios.

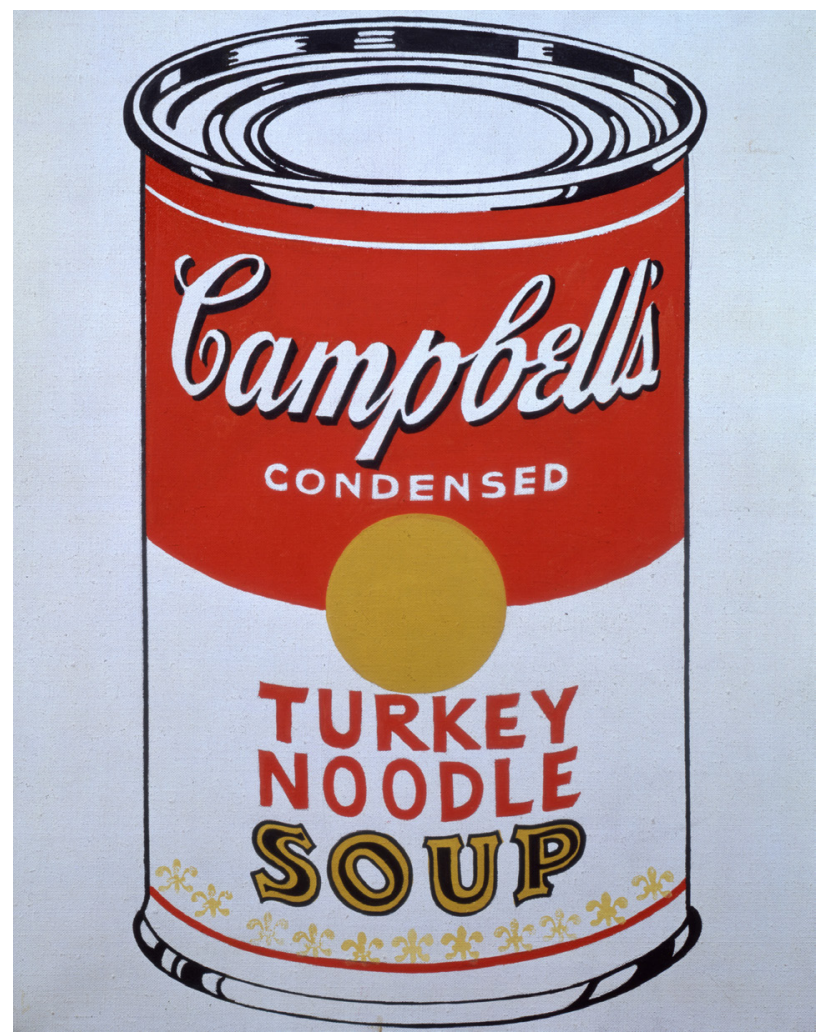

1. Andy Warhol, Lata de sopa Campbell, 1962. The Sonnabend Collection Foundation. (C) The Andy Warhol Foundation for the Visual Arts, Inc.NEGAP, Málaga, 2018

Pero hay mucho más. La exposición nos brinda en paralelo la oportunidad de ver algunos de sus trabajos pictóricos más conocidos, esos que realizó entre 1962-1968, conocido como su periodo clásico: Three Coke Bottles (1962), Gold Marilyn (1962), Campbell's Soup Can (1962), Liz Taylor (1963), Brillo Box (1964-1968), Big Electric Chair (1967), etc. son solo una pequeña muestra del repertorio expuesto.

Organizada de forma cronológica, arranca en 1949 cuando Andy Warhol se traslada a Nueva York para trabajar como dibujante de revistas de moda, momento en que, diseño tras diseño, vemos fraguarse al artista. Especialmente con la serie de dibujos Doce sombreros que incluye algunos 


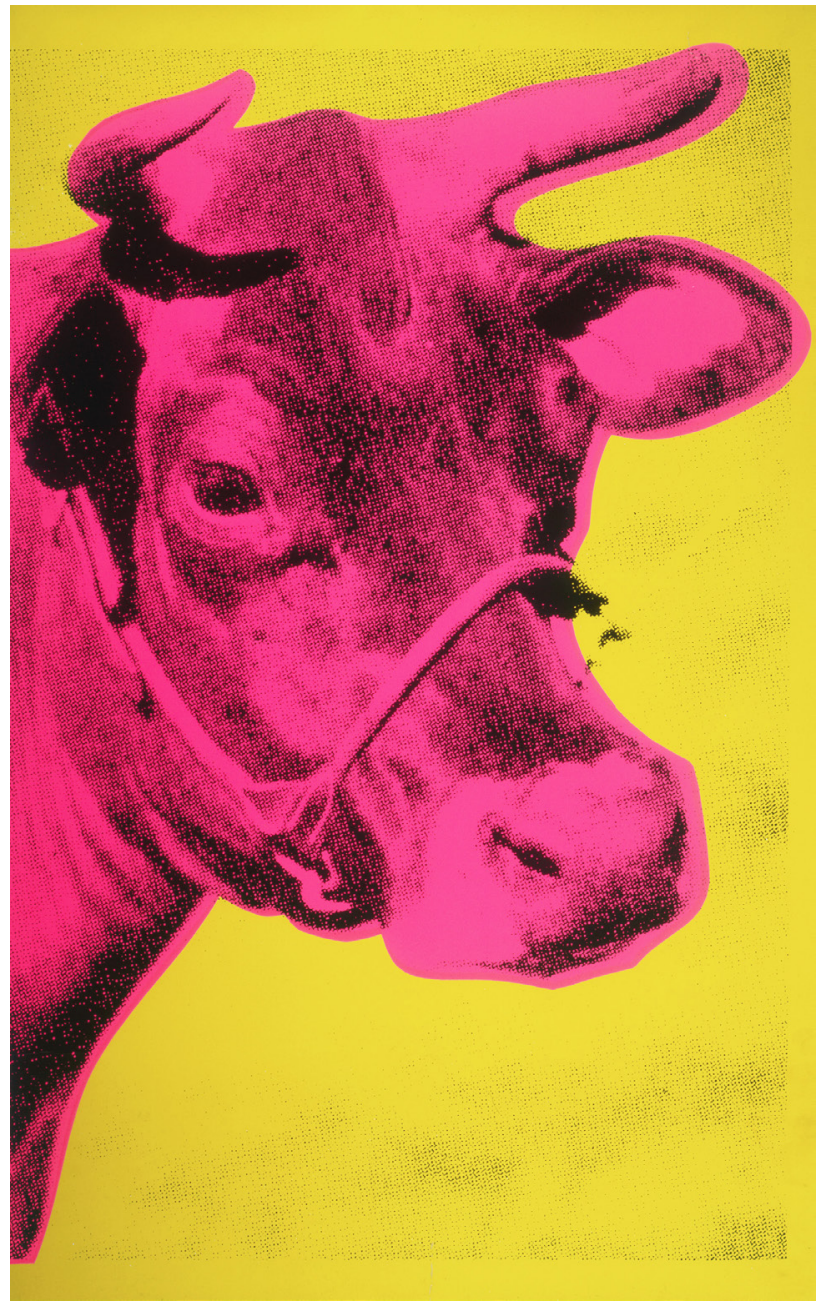

2. Andy Warhol, Vaca, 1966. The Andy Warhol Museum, Pittsburgh; colección fundacional, aportación de The Andy Warhol Foundation for the Visual Arts, Inc., inv. 1998.1.2379. (C) 2018. The Andy Warhol Museum, Pittsburgh, PA, a museum of Carnegie Institute. Todos los derechos reservados. @The Andy Warhol Foundation for the Visual Arts, Inc.NEGAP, Málaga, 2018

como Pirate Hat, Scarlett O'Hara o Toreador (1958), realizados en tinta. Estos cuelgan en la pared, a modo de prototipo, uno junto a otro; perfilados en negro y con un fuerte toque de color como relleno. Podrían ser plenamente pop si no fuera porque están realizados a mano, lo que les confiere cierta artesanía. Pero tanto el formato cuadrangular como la temática y estilo nos hablan del Warhol más clásico. En estos bocetos además de apreciar cómo opera la magia del marketing (instintivamente seleccionamos nuestro favorito, el que nos compraríamos) observamos la magia del artista, porque ante la ausencia de una cabeza humana nos hace proyectarnos a nosotros mismos portando uno. Este «efecto invocativo» que tienen pierde fuerza al verlos contextualizados, trasladados al papel brillante de Harper's Bazaar (colección de Paul Maréchal).

Una vez dejamos la sala dedicada a sus diseños gráficos (que incluye un par de dibujos de Julia Warhola), nos precipitamos sobre el gran lienzo S\&H Green Stamps (1962), que supone un antes y un después en su carrera. Su forma de trabajar cambia tras finalizar este gran cuadro, pues descubre la serigrafía, lo que «le permite acelerar el proceso artístico, así como conseguir el efecto de cadena de montaje [deseado]». Estamos ante una obra que opera aún en su anterior estadio (la década de los cincuenta, la dedicada al diseño), pero que anuncia la poética en torno a la cual girará su obra en los sesenta: repetición, serialización, imitación, falta de narratividad en unas obras que son, a su vez, tremendamente evocadoras. Especialmente lo son aquellas que reproducen bienes de consumo como Three Coke Bottles (1962) -donada por la propia fundación del artista al Museo de Andy Warhol en Pittsburgh-, en la que las botellas están flotando en el espacio a modo de sueño, de recuerdo, tornándonos gradualmente nostálgicos, sin saber exactamente por qué. A diferencia de los sombreros a los que nos referíamos antes, aquí no queremos saciar nuestra sed, no elegimos una coca-cola: "Lo que consigue filtrarse en las pinturas de Warhol es el logotipo de [coca-cola] o, mejor dicho, un símbolo producido en serie, no el producto contenido en la [botella] en sí», leemos también en el catálogo.

Se produce por lo tanto un bonito paralelismo: el contenido de las coca-colas no está en el cuadro, como tampoco lo está el pintor. Se trata nuevamente de superficies, de reflejos: "la gente siempre me dice que soy un espejo, y si un espejo se mira en otro espejo. ¿Qué puede verse?» Lo que se ve es el reflejo del espectador, su estado emocional. $Y$ este es uno de los grandes logros de Andy Warhol: salirse del cuadro, vaciar su contenido, para que vertamos en él nuestras propias emociones.

Avanzando en la exposición hacia la década de los setenta, nos encontramos con dos grupos de pinturas: el primero está compuesto por dos retratos de cabeza de vaca Cow (1976); el otro, por un conjunto de seis cuadros de flores Flowers (1964). Hasta ahora hemos visto que Warhol 
eludía el tema principal en sus cuadros, como por ejemplo con Nine Jackies (1964) que pese a mostrar nueve retratos de Jackie, nos hace pensar en el presidente asesinado. Con Flower Paintings y Cow, sin embargo, invierte ese proceso, y nos invita a utilizar la retina, lo cual parece todo un desafío, teniendo en cuenta que en la misma sala hay un Screen Test con el rostro de Marcel Duchamp, quien precisamente rompió con ese modo de mirar arte. Si nos fijamos bien en estas Flowers, nos parecen siniestras más que alegres: están desenfocadas, saturadas, y el césped del que surgen es punzante y cortante. Igualmente pasa con Cow, que no pace libremente en el campo, su semblante es triste, el amarre junto a la boca así lo dice.

Mirando el papel pintado que cubre la pared donde cuelga el gran retrato de Mao (1972), con el llamativo patrón de lunares morados repitiendo la misma cara, es imposible no pensar en la época en la que trabajó como escaparatista. Warhol utiliza a menudo esos conocimientos en las galerías y museos donde expuso, con el claro objetivo de llamar la atención de los viandantes. Ejemplo de ellos es el Moderna Museet de Estocolmo, donde empapeló todo el edificio con el rostro fucsia de vaca en 1968.

En la última parte del recorrido, con la multitud de retratos de personajes famosos y ricos de gran tamaño, realizados a partir de fotos polaroids, José Lebrero, el comisario de la muestra, contrapone el mundo de la fama, el lujo, y las fiestas (el retrato de Miguel Berrocal, de 1981, está realizado con polvo de diamante), con el de la muerte y el sufrimiento. De repente, cuando nos enfrentamos a Big Electric Chair (1967) o a Horizontal Orange Car Crash (1963) es como si alguien, sin previo aviso, hubiese cortado la música y apagado las luces del environment multisensorial que recrea el Exploding Plastic Inevitable. En este diálogo extraño y lógico que se produce entre la fama y la muerte (temática constante en la obra de Warhol), encontramos un nuevo paralelismo en el rechazo a la mirada. Los retratos de celebridades son inquietantes y fuerzan un vistazo rápido, mientras que Horizontal Orange Car Crash (1963) directamente interrumpe la contemplación. ¿Alguién capaz de ver algo? La imagen, debido a los procesos a los que le somete Warhol, apenas

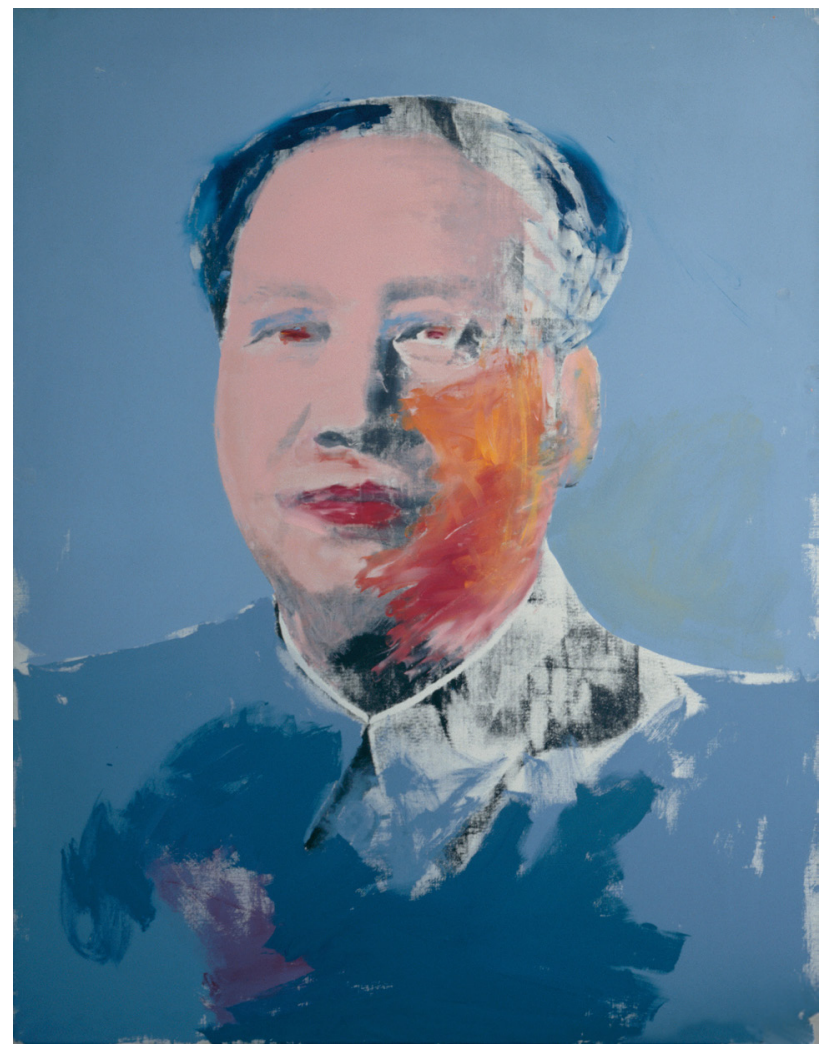

3. Andy Warhol, Mao, 1972. (C) Josep Suñol, Barcelona. (C) The Andy Warhol Foundation for the Visual Arts, Inc.NEGAP, Málaga, 2018

nos permite ver; como si el accidente la hubiera quebrado, y no se hubiera limitado solo a deformar los cuerpos.

Nunca miramos un cuadro de Warhol. Siempre somos expulsados, por un motivo u otro, de su superficie. La última pieza de la exposición es una Oxidation Painting o Piss Painting, realizada en 1978. Como su nombre indica, está realizada con la orina directa que Warhol, o algunos de sus asistentes, vertía directamente sobre los lienzos. El resultado era un cuadro abstracto y mimético, a la vez. Estas pinturas con pis aparecieron cuando parte de la crítica empezaba a cuestionar sus retratos polaroids y su artisticidad.

Inmaculada Molina 